\title{
Knowledge of antibiotic resistance and antibiotic prescription practices among prescribers in the Brong Ahafo Region of Ghana; a cross-sectional study
}

Kwaku Poku Asante ${ }^{1 *}$, Ellen Abrafi Boamah', Martha Ali Abdulai ${ }^{1}$, Kwame Ohene Buabeng ${ }^{2}$, Emmanuel Mahama ${ }^{1}$, Francis Dzabeng ${ }^{1}$, Edith Gavor ${ }^{3}$, Edith Andrews Annan ${ }^{4}$, Seth Owusu-Agyei ${ }^{1}$, Martha Gyansa-Lutterodt ${ }^{3}$ and On behalf of the Ghana Antimicrobial Resistance Working Group

\begin{abstract}
Background: Antibiotic resistance (ABR) has become a major public health challenge in most parts of the world including Ghana and is a major threat to gain in bacterial disease control. The role of prescribers in the control of antibiotics is identified as crucial in developing interventions to control ABR. To guide policy recommendations on $A B R$, a study was carried out among prescribers to identify gaps in their knowledge of ABR and to document their prescription practices.

Method: A cross-sectional survey was conducted among prescribers from both public and private facilities in the Brong Ahafo Region of Ghana using both quantitative and qualitative methods in 2014.

Results: Three hundred and seventy nine prescribers participated in the quantitative study and a subset of 33 participated in in-depth interviews. Majority (50.0\%) of the prescribers interviewed were nurses. Most (51.0\%) of the prescribers were located in hospitals. Knowledge of ABR was high among all the prescribers. About $80.0 \%$ percent of all prescribers agreed that the antibiotics that are currently used could lose its efficacy in future. There is no singular formal source of information on antibiotic resistance. The prescribers held a strong perception that antibiotic resistance is imminent though their knowledge on various resistant bacterial strains was limited. Prescribers attributed ABR burden to factors such as poor prescription practices and limited ABR control measures. The prescription practices of the prescribers vary but were mostly inappropriate among the lower cadre.
\end{abstract}

Conclusion: The knowledge of ABR is high among prescribers. There is however a gap in the knowledge and perception of optimal antibiotic prescription practices among prescribers. There is the need for a formal source of information on ABR to support prescriber's antibiotic prescription practices.

Keywords: Antibiotic resistance, Prescribers, Knowledge, Prescription, Practices

\footnotetext{
* Correspondence: kwakupoku.asante@kintampo-hrc.org

${ }^{1}$ Kintampo Health Research Centre, Ghana Health Service, KintampoBrong

Ahafo RegionGhana

Full list of author information is available at the end of the article
} 


\section{Background}

Antibiotic resistance (ABR) has become a major public health challenge in most parts of the sub-Saharan Africa including Ghana $[1,2]$. Several studies have reported the escalating prevalence of ABR to cheap and available antibiotics in less developed countries [3-7]. For instance some studies carried out in Ghana in 2011 showed that the bacterial resistance to drugs such as chloramphenicol $[8,9]$, tetracycline, ampicillin and co-trimoxazole is high $(>70 \%)[5]$.

The high burden of ABR has been an existing concern $[10,11]$ that has the potential of impeding appropriate health care [12] and reducing the success of child survival especially in developing countries [13] where infectious diseases are still high [14, 15], health systems are weak [16] and where the high levels of poverty [17] may make new efficacious antibiotics inaccessible to many patients. If unattended to, the effects of ABR will be similar to the consequence of chloroquine resistance observed in the late 1990 s i.e. a reversal of success made to disease control [13, 18-20].

ABR can be associated with misuse of antibiotics as a result of several factors including inappropriate prescription by prescribers and misuse of antibiotics by patients $[5,12,21]$. Inappropriate prescription of antibiotics is found to be positively correlated with inappropriate use of antibiotics [21]. Interventions to curtail the increasing burden of ABR are therefore urgently needed. Many intervention programs [22] including education for prescribers and consumers (population) have been recommended to help elicit the judicious and appropriate use of antibiotics [23].

Ghana recognizes the increasing burden of $A B R$ and is in the process of establishing policies to prevent and manage it. The role of prescribers is identified as crucial in developing interventions to control ABR [24]. The knowledge, perception, and practices of prescribers on antibiotic use and resistance was conducted to identify gaps to guide policy recommendations to curb ABR in Ghana.

\section{Method}

\section{Study design}

A cross-sectional survey was conducted among prescribers from both public and private facilities in the Brong Ahafo Region of Ghana using both quantitative and qualitative methods from January to March 2014.

\section{Study area}

Brong Ahafo Region is one of the ten regions in Ghana. The region is made up of 27 districts and municipalities. It is the second largest region in Ghana and spans across a total landmass of $39,557 \mathrm{~km}^{2}$. Majority of the population are Akans. Christianity is the most common religion
(70.8\%) among the population. Illiteracy rate is high: $48.5 \%$ of persons aged 15 years and above cannot read or write in any language and about $42.0 \%$ of children are not in school [25]. The study area has one regional hospital, 27 district/municipal hospitals, 35 health centers and 102 Community Based Health Planning and Service (CHPS) compounds. These health facilities are classified into levels A, B and C. Level A is a CHPS compound, level $\mathrm{B}$ is a health center and level $\mathrm{C}$ is a hospital. Level $\mathrm{C}$ facilities serve as referral centers for the levels $\mathrm{A}$ and B facilities. There are 118 Medical Doctors (MD), 387 Physician Assistants (PA), 606 general nurses and 1094 Community Health Officers (CHOs) in the region [26]. In Ghana, the training duration for community health officers, nurses, physician assistants and medical doctors is $2,3,4$ and 6 years respectively.

\section{Study approach}

Quantitative approach

Sampling procedure Medical doctors, physician assistants, nurses and community health officers were recruited to participate in the study. In each health facility, a list of medical doctors, physician assistants, nurses, and community health officers was obtained. The names of all prescribers at each health facility was written on paper and concealed by folding. The prescribers interviewed were randomly selected using a lottery method. The prescribers whose names were selected participated in the study. In cases where the number of prescribers present were equal to or less than the number required, all the prescribers were interviewed.

Quantitative data collection tool All selected respondents were consented and interviewed by trained research officers, using pretested close ended questionnaires. A two paged tool with 38 questions was used to collect the quantitative data. Questions were asked to explore the knowledge of prescribers on rational antibiotic use. Prescribers responses to disease symptoms and hypothetical case scenario management was also used as a proxy to assess their knowledge on antibiotic use. The data collection instruments were pre-tested among the different category of study participants (3 medical doctors, 2 physician assistants, 5 nurses and 2 community health officers) whose data were not included in the final analysis. The questions and approach of data collection was modeled on the WHO's standard methodology for investigating drug use in health facilities [27].

\section{Qualitative approach}

In-depth interviews In- depth interviews were conducted among a subset of prescribers until there was no new emerging issues. The moderator was guided by a two paged tool with open ended questions. The in-depth 
interview tool was used to explore the perception of prescribers on ABR and patient demand for antibiotics.

The interviews were conducted in English. The moderator sought for the respondent's consent to record and take notes on all discussions and assured respondent of confidentiality, anonymity and privacy. All recorded interviews were transcribed verbatim. Interviews were conducted between 1 and $2 \mathrm{~h}$ among the doctors and physician assistants.

Sample size calculation The sample size was calculated using STATA version 12 (StataCorp, College Station, Texas 77,845 USA) It was assumed that about $70.0 \%$ of prescribers would know about ABR. At a power of 80 and $95 \%$ confidence level, a minimum of 374 prescribers was required to estimate the knowledge of $\mathrm{ABR}$ among prescribers in the study area assuming a worst estimate of not greater than $63.0 \%$.

Data management Completed quantitative questionnaires were checked for completeness and consistency prior to further data management at the Kintampo Health Research Centre Computer Laboratory. Data was double entered into a password-protected Microsoft FoxPro version 9.0 database. In order to protect the integrity of participants' responses from interviews and survey questionnaires, all data related to the person was de-identified. Qualitative data was transcribed verbatim and coded electronic data are stored in passwordprotected computers. Data in hard copies, including survey questionnaires have been kept in locked boxes/ file cabinets. Only members of the study team have access to project data. All data is reported as anonymous without making reference to specific individuals.

Data analysis STATA version 11 was used to analyze data from the survey. Simple proportions have been used to describe categorical and numerical data respectively. The Fisher's exact was performed to test for significant association between knowledge level and category of prescribers.

In the qualitative analysis, a coding list was generated based on common themes that arose from the interviews. At least two research staff independently reviewed the data, to formulate preliminary coding and to ensure inter coder reliability and data quality. Established codes were applied to all transcripts for final analysis. QSR Nvivo version 10 qualitative software was used for the qualitative data management. Transcripts were reviewed for thematic content. The findings are presented using quotes from interviews to illustrate the major themes.

\section{Results}

A total of three hundred and seventy nine prescribers participated in the quantitative study and a subset of 33 participated in in-depth interviews. Majority $(50.0 \%)$ of the prescribers interviewed were nurses (Table 1). Thirteen percent of prescribers had practiced for more than 10 years (Table 1). Most (51.0\%) of the prescribers were located in Level C facility type (Hospitals) (Table 1).

\section{Knowledge of $A B R$ and use among prescribers}

About $81.8 \%$ of all prescribers agreed that the antibiotics that are currently used may not be effective in future. The proportion of prescribers who agreed to this was significantly highest among doctors (96.1\%) compared with community health officers (CHOs) (69.0\%) $p<0.01$ (Table 2a).

Nineteen percent of the prescribers agreed that antibiotics can be added to malaria prescriptions to make patients recover faster. This was significantly higher among $\mathrm{CHOs}$ (38.0\%) compared with doctors (3.9\%) $p<0.01$. Compared with $\mathrm{CHOs,} \mathrm{a} \mathrm{significantly} \mathrm{high} \mathrm{pro-}$ portion of doctors agreed that the use of antibiotics could lead to dangerous allergies which could cause

\begin{tabular}{ll} 
Table 1 Profile and Length of Service of prescribers $(N=379)$ \\
\hline Variable & $\mathrm{n}(\%)$ \\
\hline Sex & $157(41.0)$ \\
Male & $222(59.0)$ \\
Female & \\
Profession/type of respondent & $51(13.0)$ \\
Doctor & $69(19.0)$ \\
Physician assistant & $188(50.0)$ \\
Nurse & $71(18.0)$ \\
Community Health Officer & \\
Length of service & $77(20)$ \\
0-1 year & $181(48)$ \\
2-4 years & $73(19)$ \\
5-10 years & $48(13)$ \\
More than 10 years & \\
Number of years working at present facility & $148(39)$ \\
0-1 year & $155(41)$ \\
2-4 years & $60(16)$ \\
5-10 years & $16(4)$ \\
More than 10 years & $144(38)$ \\
Facility type & $193(51)$ \\
Level A (CHPS) & \\
Level B (Health centre/Clinics) & \\
Level C (Hospitals) & $11)$ \\
\hline
\end{tabular}


Table 2 Knowledge of ABR and antibiotic use among health professionals

\begin{tabular}{l} 
Variables \\
\hline Possibility of antibiotics to stop \\
working in future
\end{tabular}

Agree
Disagree
Don't know
Antibiotics are effective in bacterial
infection management

Agree
Disagree
Don't know

Doctor Physician assistant

$(n=51)$

$(n=69)$

\section{Nurse}

$(n=188)$

$\begin{array}{ll}49(96.1) & 64(92.8) \\ 2(3.9) & 5(7.2) \\ 0(00) & 0(00)\end{array}$

$\begin{array}{ll}51(100) & 67(97.1) \\ 0(00) & 2(2.9) \\ 0(00) & 0(00)\end{array}$

Antibiotics are effective in viral infection management

$\begin{array}{lll}\text { Agree } & 0(00) & 4(5.8) \\ \text { Disagree } & 51(100) & 64(92.8) \\ \text { Don't Know } & 0(00) & 1(1.4)\end{array}$

Antibiotics are effective in protozoal infection management

Agree
Disagree
Don't know

Antibiotics are effective in fungal infection management

Agree
Disagree
Don't Know

Antibiotics are effective in managing common cold

Agree
Disagree
Don't Know

Antibiotics help patients to recover faster when added to malaria treatment

Agree
Disagree
Don't know

Antibiotics should be prescribed before lab tests are done

Agree
Disagree
Don't know

Very expensive antibiotics can be discontinued when patient is better

$\begin{array}{lll}\text { Agree } & 8(15.7) & 10(14.5) \\ \text { Disagree } & 43(84.3) & 59(85.5) \\ \text { Don't Know } & 0(00) & 0(00)\end{array}$

$\begin{array}{ll}2(3.9) & 3(4.3) \\ 49(96.1) & 66(95.7) \\ 0(00) & 0(00)\end{array}$

$\begin{array}{ll}12(23.5) & 5(7.2) \\ 38(74.5) & 64(92.8) \\ 1(2.0) & 0(00)\end{array}$

$\begin{array}{ll}15(29.4) & 20(29.0) \\ 35(68.6) & 48(69.6) \\ 1(2.0) & 1(1.4)\end{array}$

$\begin{array}{ll}11(21.6) & 20(29.0) \\ 40(78.4) & 49(71.0) \\ 0(00) & 0(00)\end{array}$

$5(9.8)$

$10(14.5)$

$46(90.2)$

57 (82.6)

$0(00)$

$2(2.9)$

92 (48.9)

91 (48.4)

$5(2.7)$

(56.3)

$31(43.7)$

$0(00)$

21 (29.6)

35 (49.3)

$15(21.1)$

$(40.1)$

186 (49.1)

41 (10.8)

$\begin{array}{lll}114(60.6) & 48(67.6) & 193(51.0) \\ 67(35.7) & 20(28.2) & 176(46.4) \\ 7(3.7) & 3(4.2) & 10(2.6)\end{array}$

$$
5(2.7)
$$

42 (22.3)

$136(72.3)$

27 (38.0)

37 (52.1)

$10(5.3)$

$7(9.9)$

74 (19.5)

288 (76.0)

$17(4.5)$

$147(38.8)$
$225(59.4)$
$7(1.8)$

$<0.01$

19 (10.1)

12 (16.9)

48 (12.7)

324 (85.5)

$3(00)$

$56(78.9)$

7 (1.8)

3 (4.2)

$38(20.2)$
$143(76.1)$

20 (28.2)

49 (69.0)

76 (20.1)

294 (69.0)

2 (2.8)

9 (2.4)

0.70

$<0.01$

$<0.01$

$<0.01$ 
Table 2 Knowledge of ABR and antibiotic use among health professionals (Continued)

\begin{tabular}{|c|c|c|c|c|c|c|}
\hline \multicolumn{7}{|c|}{$\begin{array}{l}\text { Antibiotics use might lead to } \\
\text { dangerous allergies which could } \\
\text { cause death }\end{array}$} \\
\hline Agree & 45 (88.8) & 55 (79.7) & $121(64.4)$ & $41(57.7)$ & $262(69.1)$ & $<0.01$ \\
\hline Disagree & $6(11.8)$ & $12(17.4)$ & $50(26.6)$ & $23(32.4)$ & $91(24.0)$ & \\
\hline Don't Know & $0(00)$ & $2(2.9)$ & $17(9.0)$ & $7(9.9)$ & $26(6.9)$ & \\
\hline \multicolumn{7}{|c|}{$\begin{array}{l}\text { Antibiotics will always be effective in } \\
\text { the treatment of same infections in } \\
\text { the future }\end{array}$} \\
\hline Agree & $1(2.0)$ & $12(17.4)$ & $57(30.3)$ & $23(32.4)$ & $93(24.5)$ & $<0.01$ \\
\hline Disagree & $49(96.0)$ & 55 (79.7) & $125(66.5)$ & 39 (54.9) & $268(70.7)$ & \\
\hline Don't Know & $1(2.0)$ & $2(2.9)$ & $6(3.2)$ & $9(12.7)$ & $18(4.8)$ & \\
\hline \multicolumn{7}{|c|}{$\begin{array}{l}\text { ABR is due to the normal correct use } \\
\text { of Antibiotics }\end{array}$} \\
\hline Agree & $2(3.9)$ & $2(2.9)$ & $30(16.0)$ & $20(28.2)$ & $54(14.2)$ & $<0.01$ \\
\hline Disagree & $48(94.1)$ & 67 (97.1) & $151(80.3)$ & 45 (63.3) & $311(82.1)$ & \\
\hline Don't Know & $1(2.0)$ & $0(00)$ & $7(3.7)$ & $6(8.5)$ & $14(3.7)$ & \\
\hline \multicolumn{7}{|c|}{$\begin{array}{l}\text { ABR is due to the use of Antibiotics } \\
\text { when not prescribed }\end{array}$} \\
\hline Agree & $44(86.3)$ & 63 (91.3) & $153(81.4)$ & $53(74.6)$ & $313(82.6)$ & 0.03 \\
\hline Disagree & $7(3.7)$ & $5(7.2)$ & $30(16.0)$ & $11(15.6)$ & $53(14.0)$ & \\
\hline Don't Know & $0(00)$ & $1(1.4)$ & $5(2.7)$ & $7(9.9)$ & $13(3.4)$ & \\
\hline
\end{tabular}

death $(p<0.01)$ and disagreed that antibiotics will always be effective in the treatment of same infections in the future, $p<0.01$ (Table $2 b$ ).

Sources of knowledge about antibiotic use and resistance The sources of information on antibiotic use and resistance among the prescribers included email alerts from platforms they subscribe to, lectures at general meetings of professional associations, books, and GHS/FDB bulletin or circulars (Table 3). The core of their knowledge was acquired during their formal training as demonstrated in the comment below:

"Aside my knowledge from school, I also learn from the BNF- British National Formulary, it has all the medications that we prescribe so, if you want to check the dose, you just refer to it and also from our standard treatment guide and also from senior colleagues" (IDI, MD)

There were no differences in the sources of information among the different health professionals and there was no specific channel for obtaining information on ABR as alluded to below.

"Yes because we don't have any official source of information about antibiotics and when you browse [the internet] the information is not straight forward.
If we are able to get a main source of information about antibiotics it will be well" (IDI, PA)

Barriers to prescribers access to antibiotic related information is limited by lack of internet facility, lack of a uniform source of information and lack of local data on patterns of $\mathrm{ABR}$.

\section{Perception of the burden of ABR}

Generally, the prescribers perceived $A B R$ as a very crucial issue that needs to be addressed. Their perception

Table 3 Health professionals source of information on $A B R$ and use

\begin{tabular}{|c|c|}
\hline Source of information & Examples \\
\hline Electronic media & $\begin{array}{l}\text { - Mobile phone messaging e.g. Short Messaging } \\
\text { Service (SMS) } \\
\text { - Internet } \\
\text { - Email alerts by subscription }\end{array}$ \\
\hline Prints & $\begin{array}{l}\text { - Bulletins for Ghana Health Service or Food and } \\
\text { Drugs Authority } \\
\text { - British National Formulary } \\
\text { - Text books }\end{array}$ \\
\hline Meetings & $\begin{array}{l}\text { - Professional meetings such as annual general } \\
\text { meeting } \\
\text { - Workshops } \\
\text { - Lectures organized by pharmaceutical } \\
\text { companies } \\
\text { - In service training } \\
\text { - Peers and senior colleagues }\end{array}$ \\
\hline
\end{tabular}


of ABR burden was mainly informed by its impact on Multidrug Resistant Mycobacterium tuberculosis control and to a less extent about the control of other infections such as Methicillin Resistant Staphylococcus aureus. The prescribers perceived ABR could have serious consequences on mortality trends and health expenditure as demonstrated below:

"That is the most dangerous thing that can happen to mankind. We may move to the last limit where we cannot get any antibiotics to treat certain diseases. Talking about antibiotics, if you look at treatment of $\mathrm{TB}$, which is a bacterium. We are strict because it is a combination course. If you joke and one of them develops a resistance, the other three cannot do anything. And to get another drug that will work like the former one doesn't take 1 day. It takes a period. And the cost of it is also another thing.... So we need to be careful with antibiotics especially if mankind wants to live long on this earth" (IDI, PA)

\section{Perception of causes of ABR}

Prescribers perception of causes of ABR were several. Their perceptions include antibiotic over prescription, irrational prescription of antibiotics, patient non-compliance to medications, unregulated dispensing of antibiotics leading to over the counter purchases. During the in-depth interviews the prescribers shared their perceptions regarding ABR from different perspectives.

“...Most of the hospitals also don't have machines for culture sensitivity to actually isolate the real bacteria that is causing the disease. So just prescribing any form of antibiotic may increase the resistance. (IDI, PA)

"...antibiotic resistance is possible because in Ghana .., you can go to any drug store and buy any antibiotics without any prescription or these days we don't know the source of medication that we are getting whether they are the correct or the fake ones. The efficacy level is questionable." (IDI, MD)

However, health facility preventive measures such as hand washing, use of cleaning solutions, and sterilization were rarely mentioned by the prescribers.

\section{Practices of antibiotic use and health worker's rational in selecting antibiotics}

To learn about prescription practices, Upper Respiratory Tract Infections (URTI) was presented as case scenario to prescribers.

Most of prescribers indicated that they diagnose URTI using the patient's complaints and physical examination and to a less extent laboratory confirmation of the causative agents. URTIs are often treated presumptively with antibiotics of varying types depending on the disease progression or severity at presentation. In some cases, second and third generation antibiotics are primarily used. Not all prescribers adhere to the Ghana National Treatment Guidelines in their choice of antibiotics for treating URTI. This is illustrated by the following quotes:

"Most of the URTIs practically are viral infections and not bacteria. However, if I establish that the cause of the URTI is a bacteria then I give antibiotics. As first line treatment I give amoxicillin for the typical ones or azithromycin for the atypical ones. But if the patient have already gone for the first line treatment drug, then I give the second line treatment drugs like amoxiclav and other higher antibiotics. But for kids and toddlers I give flucloxacillin for the start because the cause is usually gram positive, staph [Staphyloccocus] and strep.[Streptococcus] infection" (IDI, MD)

Prescribers rationale for their choice of antibiotics in treating patients is also influenced other factors such as patient's ability to pay for the antibiotic, antibiotic availability patient drug history, allowable restrictions of antibiotic at the level of the facility, allowable antibiotics on insurance protocols, feedback on recovery due to treatment, patient age, medical history of the patient, and clinician wanting to impress patient. A prescriber had this to say:

"The number one reason is the insurance. You always want to prescribe what the patients will get in your facility; the second factor is affordability of the patient, if the patient can afford some of the high ones you can prescribe for them and the third factor will be previous drug history, what has the patient taken before coming to you. You don't want to continue on the same line. The other factor will be patient choice, sometimes you have to agree with the patient" (IDI, MD)

The prescribers shared different experiences on patient's demand for antibiotics. Prescribers do not mostly consider patients expectations in the prescription of antibiotics. However, patients who are able demonstrate why they should be prescribed a particular antibiotic may receive what they ask for. Also, patients who may have had a bad experience with a particular antibiotic may not accept the same the antibiotic if it is prescribed for them. Patients who are educated demand specific antibiotics but the less educated ones accept whatever is prescribed for them.

Prescribers also hold the perception that they know the best drugs for the patients' illness. 
“.... No! As a clinician no! If the patient comes to me with an expectation, then it is my job to explain to the patient... in certain cases it maybe what you wanted to prescribe then it makes your work easier but if it is not, I will take my time and educate the patient on what I think is best for the patient" (IDI, MD)

"You will have that problem of being influenced by patients who are educated and also the health staff themselves on the UTI (urinary tract infections), they will request specifically for some type of antibiotic but for the general population, they rely on what we prescribe for them. " (IDI, MD)

\section{Knowledge of health facility infection control committee and drug or therapeutic management committees}

Knowledge on the availability of an infection control committee was assessed among the prescribers. About $47.0 \%(178 / 379)$ of prescribers indicated non -availability of infection control committees in their facilities. Only $16.4 \%$ of prescribers reported of functional Drug Therapeutics Committee (DTC) in their facility. There was a significant difference in prescribers knowledge of a functional DTC in their facility (19.6\% doctors, $20.3 \%$ PAs, $18.1 \%$ nurses and $5.6 \%$ CHOs; $p<0.01$ ).

\section{Discussion}

Prescribers are an important group of persons in the control of ABR. They are most likely to prevent ABR in their practice and advice patients on ABR if they are themselves aware of ABR. In this study, the knowledge and perception of antibiotic resistance among prescribers in the Brong Ahafo Region of Ghana was assessed. Most cadres of prescribers interviewed were knowledgeable about ABR. Most prescribers knew that the antibiotics we are using today can be ineffective in the future. There was however a significant gap in the knowledge of antibiotic use among the health professionals especially among the lower cadre of staff. It is important that this gap is bridged as the lack of knowledge of appropriate antibiotic use is likely to lead to inappropriate antibiotic stewardship and subsequently lead to antibiotic resistance. An intervention to improve antibiotic knowledge and enhance antibiotic stewardship especially among the lower cadre of prescribers is very crucial because they form the majority of prescribers in health facilities and are the frontline professionals in healthcare. In Ghana, there are no systematic programs to monitor antibiotic prescription practices among prescribers [2] and the results of this study will support the call for an urgent action against ABR in Ghana [5, 28].

Several varying factors such as existing health care systems influence antibiotic use and misuse in various parts of the world [29, 30]. The absence of diagnostic test at health facilities is likely to affect adherence to disease treatment protocols to prevent ABR. Almost all the prescribers interviewed knew that antibiotics are used to manage bacterial infections. However, though some prescribers knew that common cold are mostly caused by viral infections, they presumptively treat patients with antibiotics. The main reason for presumptive treatment of suspected bacterial disease is mainly due to the lack of laboratory facilities to isolate the causative organisms and also due to the syndromic approach in patient management at the community level. This practice is likely to lead to over prescription of antibiotics and subsequently bacterial resistance to available cheap antibiotics and poor management of other nonbacterial diseases. Rapid diagnostic test that could differentiate between bacterial and other infections will be important in supporting decisions to prescribe antibiotics and to reconsider syndromic approach to treatment at the lower level of care [27].

Prescribers were worried about ABR and the fact that it can be a very huge public health set back. This knowledge of the potential problem of ABR creates the opportunity for adequate health education among all cadres of prescribers about ABR.

Our finding that amoxicillin is the first line presumptively prescribed antibiotic is similar to reports of other studies that indicates that the first generation of penicillin is mostly prescribed [31, 32]. There is increasing evidence that a number of gram-negative organisms are developing resistance to amoxicillin and the frequent presumptive use of it may have a role in the emerging resistance $[33,34]$.

In this study, prescribers' prescriptions were sometimes influenced by patient's request. This finding is similar to that reported by Rodrigues et al. [35] and Abera et al. [36] In their studies, patients' influence on prescribers to prescribe specific antibiotics was identified as one of the main factors for excessive antibiotic prescription. Though patient involvement in disease management is important to enhance disease cure, it is crucial that prescribers prescribe antibiotics based on scientific and medical basis. Prescribers rationale for their choice of antibiotics should therefore be explained to patients to enhance drug compliance.

In this study, there was no knowledge of an established ABR surveillance system where prescribers can source for information on ABR patterns in areas where they work. This is not surprising as Ghana has no formal ABR surveillance system as occurs in all other countries in the World Health Organisation (WHO) African region. [37] It is important that a national or regional ABR surveillance system such as European Center for Diseases Antimicrobial Resistance Surveillance Network 
$[38,39]$ be established to regularly update and disseminate $A B R$ data to all health workers through effective platforms such as email or other electronic alerts, news bulletins, or through memos to all health facilities.

The role of hospital infection prevention protocols are important to prevention of bacterial resistant strains such as Methicilin Resistant Staploccous aureus (MRSA) [40]. In this study, the knowledge of current drug resistant strains of bacteria apart from Multidrug Resistant Mycobacterium Tuberculosis was limited. Specifically, the knowledge of extended-spectrum beta-lactamases producing Enterobacteriaceae was limited though there was an outbreak in a major hospitals in Ghana [28] and reports of other resistant bacterial stains [41, 42]. In discussing causes of drug resistance, hospital infection control was also least mentioned as potential cause of drug resistance though the Ministry of Health of Ghana has an established policy on infection control [40]. This is not surprising as less than $50 \%$ of respondents knew about their institutions infection control protocols. A functional Drug and Therapeutic Committee (DTC) in health facilities is important in ensuring rational drug prescriptions. In this study, less than $20 \%$ of respondents indicated that there was an existing functional DTC [43]. There is the need to strengthen infections control policies and DTC as institutional steps in preventing ABR.

\section{Conclusion}

The knowledge of ABR is high among prescribers. There is however a gap in the knowledge and perception of optimal antibiotic prescription practices among health professionals. There is the need for a formal source of information of ABR to support prescriber's antibiotic prescription practices.

\section{Additional file}

Additional file 1: Study materials. (PDF $186 \mathrm{~kb}$ )

\begin{abstract}
Abbreviations
ABR: Antibiotic resistance; $\mathrm{CHOs}$ : Community health officers; CHPS: Community based health program and service; DTC: Drug therapeutic committee; FDB: Food and drugs board; GHS: Ghana Health Service; IDI: In depth interviews; MD: Medical doctor; PA: Physician assistant; URTI: Upper respiratory tract infection; UTI: Urinary tract infection; WHO: World Health Organisation
\end{abstract}

\section{Acknowledgements}

The authors are grateful to the management of the following institutions and persons for their contribution to the conduct of this study: Ministry of Health and Ghana Health Service; ReACT, Ghana Antimicrobial Resistance Working Group, Regional Health Directorate and health institutions in the Brong Ahafo Region of Ghana; Kintampo Health Research Centre and all study participants.

\section{Funding}

This study was funded by the Ministry of Health, Ghana.

\section{Availability of data and materials}

The datasets used and/or analysed during the current study are available from the corresponding author or at enquiries@kintampo-hrc.org on reasonable request. The study materials are included as Additional file 1.

\section{Authors' contributions}

KPA, MGL conceived the study idea. EAB and AM lead the study implementation under the supervision of KPA, SOA, EG and MGL. The data was managed and analyzed by FD, EM, EAB, MA, KPA and SOA. The data was interpreted by KPA, EAB, MA, KB, EAA, SOA and MGL. All authors contributed to the manuscript writing and approved of the manuscript.

\section{Authors' information}

KPA is a Clinical Epidemiology and the Head of Research at Kintampo Health Research Center (KHRC) in Ghana and a member of the Ghana Antimicrobial Resistance Working Group. MGL is the Director of Pharmaceutical Services of Ghana Ministry of Health and the Chairperson of the Ghana Antimicrobial Resistance Working Group. EAB, AM, FD, EM, are Research Fellows at KHRC. SOA is an Epidemiologist and the Director of KHRC. KOB is a Pharmacist and a Senior Lecturer at the Faculty of Pharmacy and Pharmaceutical Services at the College of Health Sciences, Kwame Nkrumah University of Science and Technology, Ghana. He is also the Vice Chair Person of the Ghana

Antimicrobial Resistance Working Group. EG is the Programme Manager for the Ghana National Drugs Programme at the Ministry of Health. EAA is the Country Adviser for Medicines, Health Technologies and Laboratories at the World Health Organisation country office in Ghana.

\section{Competing interests}

Authors declare that they have no competing interest. Whether financial or non-financial.

\section{Consent for publication}

Not applicable.

\section{Ethics approval and consent to participate}

The study was approved by the Kintampo Health Research Center Scientific Review Committee, the Kintampo Health Research Center Institutional Ethics Committee (Federal Wide Assurance number 0011103) and the Ghana Health Service Ethics Review Committee. Approval was also obtained from the management of all the selected health facilities. Written informed consent was sought from respondents. Confidentiality of subjects was protected at all times and respondents were free to decline to participate at any time or to withdraw from the study.

\section{Publisher's Note}

Springer Nature remains neutral with regard to jurisdictional claims in published maps and institutional affiliations.

\section{Author details}

${ }^{1}$ Kintampo Health Research Centre, Ghana Health Service, KintampoBrong Ahafo RegionGhana. ${ }^{2}$ Faculty of Pharmacy \& Pharmaceutical Services, College of Health Sciences, Kwame Nkrumah University of Science and Technology, Kumasi, Ghana. ${ }^{3}$ Ghana National Drugs Programme, Ministry of Health, Accra, Ghana. ${ }^{4}$ World Health Organization, Ghana Country Office, Accra, Ghana.

Received: 17 December 2015 Accepted: 8 June 2017

Published online: 20 June 2017

\section{References}

1. Leopold SJ, van Leth F, Tarekegn H, Schultsz C. Antimicrobial drug resistance among clinically relevant bacterial isolates in sub-Saharan Africa: a systematic review. J Antimicrob Chemother. 2014;69(9):2337-53.

2. Gyansa-Lutterodt M. Antibiotic resistance in Ghana. Lancet Infect Dis. 2013; 13(12):1006-7.

3. Newman M, Seidu A. Carriage of antimicrobial resistant Escherichia coli in adult intestinal flora. West Afr J Med. 2002;21(1):48.

4. Mills-Robertson F, Addy ME, Mensah P, Crupper SS. Molecular characterization of antibiotic resistance in clinical salmonella typhi isolated in Ghana. FEMS Microbiol Lett. 2002;215(2):249-53.

5. Newman MJ, Frimpong E, Donkor ES, Opintan JA, Asamoah-Adu A. Resistance to antimicrobial drugs in Ghana. Infect Drug Resist. 2011;4:215-20. 
6. Newman MJ. Multiple-resistant Salmonella group G outbreak in a neonatal intensive care unit. West Afr J Med. 1996;15(3):165-9.

7. Opintan JNM. Distribution of serogroups and serotypes of multiple drug resistant Shigella isolates. Ghana Med J. 2007:41:4-8.

8. Uwe Groß SKA, de Ciman R, Iparkhan Kassimova LG, Wolfgang Rabsch UR, Marco Schulze AS, Zimmermann AO. Bacteremia and antimicrobial drug resistance over time, Ghana. Emerg Infect Dis. 2011;17(10):1879-82.

9. Opintan JA, Newman MJ, Arhin RE, Donkor ES, Gyansa-Lutterodt M, MillsPappoe W. Laboratory-based nationwide surveillance of antimicrobial resistance in Ghana. Infect Drug Resist. 2015;8:379-89.

10. Gould IM. Coping with antibiotic resistance: the impending crisis. Int J Antimicrob Agents. 2010;36(Suppl 3):S1-2.

11. Mah MW, Memish ZA. Antibiotic resistance. An impending crisis. Saudi Med J. 2000;21(12):1125-9.

12. Greenhalgh T. Drug prescription and self-medication in India: an exploratory survey. Soc Sci Med. 1987;25(3):307-18.

13. X-z S, Kirkman LA, Fujioka H, Wellems TE. Complex polymorphisms in an $330 \mathrm{kDa}$ protein are linked to chloroquine-resistant P. Falciparum in Southeast Asia and Africa. Cell. 1997;91(5):593-603.

14. Gupta I, Guin P. Communicable diseases in the South-East Asia Region of the World Health Organization: towards a more effective response. Bull World Health Organ. 2010;88(3):199-205.

15. Global, regional, and national age-sex specific all-cause and causespecific mortality for 240 causes of death, 1990-2013: a systematic analysis for the Global Burden of Disease Study 2013. Lancet. 2015; 385(9963):117-171.

16. Harries AD, Jensen PM, Zachariah R, Rusen ID, Enarson DA. How health systems in sub-Saharan Africa can benefit from tuberculosis and other infectious disease programmes. Int J Tuberc Lung Dis. 2009;13(10):1194-9.

17. Chen S, Ravallion M. The developing world is poorer than we thought, but no less successful in the fight against poverty. World Bank Policy Research Working Paper Series; 2008. http://siteresources.worldbank.org/DEC/ Resources/DevelopingworldispoorerQJE.pdf. Accessed 18 July 2017.

18. Najafi M, Lemon SM, Knobler SL, Burroughs T. The Resistance Phenomenon in Microbes and Infectious Disease Vectors: Implications for Human Health and Strategies for Containment-Workshop Summary. Washington DC: National Academies Press; 2003.

19. Greenberg AE, Ntumbanzondo M, Ntula N, Mawa L, Howell J, Davachi F. Hospital-based surveillance of malaria-related paediatric morbidity and mortality in Kinshasa, Zaire. Bull World Health Organ. 1989:67(2):189.

20. Trape J-F. The public health impact of chloroquine resistance in Africa. Am J Trop Med Hyg. 2001;64(1 suppl):12-7.

21. Thriemer K, Katuala Y, Batoko B, Alworonga J-P, Devlieger H, et al. Antibiotic prescribing in DR Congo: a knowledge, attitude and practice survey among medical doctors and students. PLoS One. 2013:8(2), e55495.

22. Chaouat G, Ledee-Bataille N, Dubanchet S, Zourbas S, Sandra O, Martal J. Reproductive immunology 2003: reassessing the Th1/Th2 paradigm? Immunol Lett. 2004;92(3):207-14.

23. Seppälä H, Klaukka T, Vuopio-Varkila J, Muotiala A, Helenius H, Lager K, et al, The effect of changes in the consumption of macrolide antibiotics on erythromycin resistance in group a streptococci in Finland. N Engl J Med. 1997;337(7):441-6

24. DACA. Antimicrobial use, resistance and containment baseline survey synthesis of findings. 2009 drug administration and control authority of Ethiopia. Addis Ababa: Management sciences for health, strengthening pharmaceutical systems (MSH/SPS); 2009.

25. Ghana Gorvernment Portal. http://www.ghana.gov.gh/index.php/aboutghana/regions/brong-ahafo. Accessed 15 Mar 2015.

26. Ghana Health Service, Brong Ahafo Regional Health Directorate 2014 Annual Report. 2015. www.ghanahealthservice.org/rhdcategory.php?ghsrid= $6 \& c i d=19$. Accessed 15 Mar 2016.

27. Shankar PR. Essential medicines and health products information portal. J Pharmacol Pharmacother. 2014;5(1):74.

28. Obeng-Nkrumah N, Twum-Danso K, Krogfelt KA, Newman MJ. High levels of extended-spectrum beta-lactamases in a major teaching hospital in Ghana: the need for regular monitoring and evaluation of antibiotic resistance. Am J Trop Med Hyg. 2013;89(5):960-4

29. Parker HM, Mattick K. The determinants of antimicrobial prescribing among hospital doctors in England: a framework to inform tailored stewardship interventions. Br J Clin Pharmacol. 2016:82:431.
30. Malla S, Dumre SP, Shakya G, Kansakar P, Rai B, Hossain A, et al. The challenges and successes of implementing a sustainable antimicrobia resistance surveillance programme in Nepal. BMC Public Health. 2014;14:269.

31. Demirbas F, Gjermo PE, Preus HR. Antibiotic prescribing practices among Norwegian dentists. Acta Odontol Scand. 2006;64(6):355-9.

32. Kamulegeya A, William B, Rwenyonyi CM. Knowledge and antibiotics prescription pattern among ugandan oral health care providers: a crosssectional survey. J Dent Res Dent Clin Dent Prospects. 2011;5(2):61.

33. Ready D, Lancaster $H$, Qureshi F, Bedi R, Mullany P, Wilson M. Effect of amoxicillin use on oral microbiota in young children. Antimicrob Agents Chemother. 2004;48(8):2883-7.

34. Kuriyama T, Nakagawa K, Karasawa T, Saiki Y, Yamamoto E, Nakamura S. Past administration of $\beta$-lactam antibiotics and increase in the emergence of $\beta$-lactamase-producing bacteria in patients with orofacial odontogenic infections. Oral Surg Oral Med Oral Pathol Oral Radiol Endod. 2000;89(2): 186-92.

35. Teixeira Rodrigues A, Roque F, Falcao A, Figueiras A, Herdeiro MT. Understanding physician antibiotic prescribing behaviour: a systematic review of qualitative studies. Int J Antimicrob Agents. 2013;41(3):203-12.

36. Abera B, Kibret M, Mulu W. Knowledge and beliefs on antimicrobial resistance among physicians and nurses in hospitals in Amhara Region, Ethiopia. BMC Pharmacol Toxicol. 2014;15:26.

37. Essack SY, Desta AT, Abotsi RE, Agoba EE. Antimicrobial resistance in the WHO African region: current status and roadmap for action. J Public Health (Oxf). 2017;39(1):8-13.

38. Hrabak J, Papagiannitsis CC, Studentova V, Jakubu V, Fridrichova M, Zemlickova H. Carbapenemase-producing Klebsiella pneumoniae in the Czech Republic in 2011. Euro Surveill. 2013;18(45):20626.

39. Cole MJ, Spiteri G, Jacobsson S, Pitt R, Grigorjev V, Unemo M. Is the tide turning again for cephalosporin resistance in Neisseria gonorrhoeae in Europe? Results from the 2013 European surveillance. BMC Infect Dis. 2015; 15:321.

40. National manual for infection prevention and control policy and a standard operating procedure for airborne diseases for healthcare practitioners. Ghana: Ministry of Health; 2011. http://www.tbghana.gov.gh/sites/default/ files/IPC\%20Policy\%20April\%202009.pdf. Accessed 15 Mar 2015.

41. Dayie NT, Arhin RE, Newman MJ, Dalsgaard A, Bisgaard M, Frimodt-Moller N, et al. Penicillin resistance and serotype distribution of Streptococcus Pneumoniae in Ghanaian children less than six years of age. BMC Infect Dis. 2013;13:490

42. Egyir B, Guardabassi L, Esson J, Nielsen SS, Newman MJ, Addo KK, et al. Insights into nasal carriage of Staphylococcus aureus in an urban and a rural community in Ghana. PLoS One. 2014;9(4):e96119.

43. Mikkelsen CM, Andersen SE. A regional DTC-led intervention to reduce the hospital costs of expensive HIV drugs. Basic Clin Pharmacol Toxicol. 2016; 119:278.

\section{Submit your next manuscript to BioMed Central and we will help you at every step:}

- We accept pre-submission inquiries

- Our selector tool helps you to find the most relevant journal

- We provide round the clock customer support

- Convenient online submission

- Thorough peer review

- Inclusion in PubMed and all major indexing services

- Maximum visibility for your research

Submit your manuscript at www.biomedcentral.com/submit 